\title{
Inbreeding Depression on Female Fertility and Calving Ease in Spanish Dairy Cattle
}

\author{
O. González-Recio, ${ }^{\star 1}$ E. López de Maturana,† and J. P. Gutiérrezł \\ *Departamento de Producción Animal, E.T.S.I. Agrónomos, Universidad Politécnica, Ciudad Universitaria s/n, 28040 Madrid, Spain \\ †Departamento de Sanidad y Producción Animal, NEIKER-TECNALIA, Granja Modelo de Arkaute. P.O. Box 46, 01080 Vitoria-Gasteiz, Spain \\ $\ddagger$ Departamento de Producción Animal, Facultad de Veterinaria, Universidad Complutense de Madrid, Avda. Puerta de Hierro s/n, \\ 28040 Madrid, Spain
}

\begin{abstract}
Inbreeding depression on female fertility and calving ease in Spanish dairy cattle was studied by the traditional inbreeding coefficient $(\mathrm{F})$ and an alternative measurement indicating the inbreeding rate $(\Delta \mathrm{F})$ for each animal. Data included records from 49,497 and 62,134 cows for fertility and calving ease, respectively. Both inbreeding measurements were included separately in the routine genetic evaluation models for number of insemination to conception (sequential threshold animal model) and calving ease (sire-maternal grandsire threshold model). The $\mathrm{F}$ was included in the model as a categorical effect, whereas $\Delta \mathrm{F}$ was included as a linear covariate. Inbred cows showed impaired fertility and tended to have more difficult calvings than low or noninbred cows. Pregnancy rate decreased by $1.68 \%$ on average for cows with $\mathrm{F}$ from 6.25 to $12.5 \%$. This amount of inbreeding, however, did not seem to increase dystocia incidence. Inbreeding depression was larger for $\mathrm{F}$ greater than $12.5 \%$. Cows with $\mathrm{F}$ greater than $25 \%$ had lower pregnancy rate and higher dystocia rate $(-6.37$ and $1.67 \%$, respectively) than low or noninbred cows. The $\Delta \mathrm{F}$ had a significant effect on female fertility. A $\Delta \mathrm{F}=0.01$, corresponding to an inbreeding coefficient of $5.62 \%$ for the average equivalent generations in the data used (5.68), lowered pregnancy rate by $1.5 \%$. However, the posterior estimate for the effect of $\Delta \mathrm{F}$ on calving ease was not significantly different from zero. Although similar patterns were found with both $\mathrm{F}$ and $\Delta \mathrm{F}$, the latter detected a lowered pregnancy rate at an equivalent $\mathrm{F}$, probably because it may consider the known depth of the pedigree. The inbreeding rate might be an alternative choice to measure inbreeding depression.
\end{abstract}

Key words: inbreeding depression, female fertility, calving ease

Received March 16, 2007.

Accepted August 12, 2007.

${ }^{1}$ Corresponding author: oscar.grecio@upm.es

\section{INTRODUCTION}

Functional traits have become increasingly important in Holstein breeding during the last decade with the goal of reducing herd costs (Miglior et al., 2005). Fertility and calving ease (CE) are among the most important functional traits from an economic point of view (Groen et al., 1997; González-Recio et al., 2004). Impaired fertility increases cost and labor in herds (Dekkers, 1991); also, female fertility is essential to continue the productive life of the cow, because pregnancy must be achieved to obtain a subsequent lactation. Calving difficulties negatively affect profitability in dairy herds as well, because it causes direct (veterinary fees, death of calf or cow, and extra farmer labor) and indirect (decreased milk yield and deteriorated female fertility) costs (Dematawewa and Berger, 1997; López de Maturana et al., 2007a,c). Both female fertility and $\mathrm{CE}$ are highly related to functional longevity, because decreased fertility and calving difficulty are among the main reasons of involuntary culling in dairy cattle (Bascom and Young, 1998; López de Maturana et al., 2007b).

The high emphasis placed on milk yield in total merit selection indexes has been pointed out as a cause of impaired functionality, because it is negatively related to most functional traits (e.g., fertility or health traits) from a genetic point of view (Dechow et al., 2001; Veerkamp et al., 2001). Inbreeding depression has also been blamed for deteriorated functionality. Several authors estimated that the average inbreeding in Holsteins has increased by 3 to $4 \%$ from 1980 to 2004 in different countries (AIPL, 2006; Croquet et al., 2006; Sewalem et al., 2006). Sewalem et al. (2006) showed that the risk of culling was augmented by $14 \%$ when inbreeding exceeded 6.25\%; meanwhile, an inbreeding coefficient higher than $10 \%$ increased age at first calving by $27 \mathrm{~d}$ (Thompson et al., 2000). However, few studies have related inbreeding with female fertility for lactating cows or with CE (Cassell et al., 2003b; Adamec et al., 2006). 
Several authors have studied crossbreeding with different breeds (Montbelliard, Brown Swiss, Jersey, or Scandinavian Red) as a possible way to offset the consequences of inbreeding depression. The different crossbred cows used in those studies presented a slight improvement of fertility and disease resistance compared with pure Holstein parents (Vesely et al., 1986; Weigel and Barlass, 2003; Heins et al., 2006). However, the viability of crossbreeding may be arguable, because the production level deteriorated, which can substantially affect profitability. Furthermore, a drastic change in management, breeding, and production system would be necessary to accommodate crossbreeding in Holstein production systems, which a priori appears unfeasible. Other solutions must be considered.

Inbreeding coefficient has been widely studied and defined (Falconer and Mackay, 1996). However, the study of its effects on functional traits has posed many challenges, because the increase in the inbreeding coefficient $(\mathbf{F})$ is not linear across generations and may lead to different conclusions depending on the pedigree depth. For example, a coefficient value of $25 \%$ can be interpreted as a very high level of inbreeding if one of its parents is an offspring of the other and no other genealogic information exists, but it can be considered as low if the animal belongs to a small population with a high pedigree depth. The relative value of the inbreeding coefficient as well as its nonlinear increase in time have been the 2 main factors of research about inbreeding depression. There may be a need to identify an alternative way of fitting inbreeding coefficients accounting for the amount of genealogic information.

Historically, several interval traits have been used to measure female fertility. However, the variation of these traits is highly dependent on management practices, such as estrous synchronization and differences in the voluntary waiting period. The number of inseminations to conception (INS) can reflect variation in both male and female fertility (González-Recio et al., 2005), and it is one of the most economically important fertility traits (González-Recio et al., 2004).

The objective of this research was to study the effects of inbreeding on female fertility (through INS) and CE in the Spanish Holstein population. The analysis was carried out comparing different levels of inbreeding, as well as developing an alternative method for fitting inbreeding coefficients, which took into account the amount of known pedigree for each animal.

\section{MATERIALS AND METHODS}

\section{Data}

Data were provided by the regional Holstein associations from 3 regions of Spain (Basque Country, Na- varra, and Gerona). The complete pedigree included 564,317 animals. Milk yield and reproductive data from all available lactations from 1994 through 2006 were used in the analysis. Calving ease data have been routinely collected by trained technicians applying the following scoring criterion: 1 = unassisted calvings; $2=$ calvings requiring slight assistance; $3=$ calvings needing help; 4 = caesareans caused by size of calf; and $5=$ caesareans for other reasons, abnormal presentations or malformations of the calf. Two subsets of data with different editing processes were generated considering either fertility or CE.

The following editing was used to create the fertility data subset: calving interval had to range from 300 to $600 \mathrm{~d}$, and records were omitted if days to first service were unknown, less than $25 \mathrm{~d}$, or greater than $160 \mathrm{~d}$. Cows with a first calving before 18 mo or after 40 mo of age were excluded. The insemination records within lactation were codified as 1 if it was followed by another $\mathrm{AI}$ in the same lactation or if no subsequent calving was registered. Otherwise, it was codified as 0 (pregnancy). The last insemination should match with a 272 to 292-d gestation length before next calving. At least 10 and 25 records were required per herd-year comparison group and service sire, respectively. Herds with an average INS less than 1.5 were removed.

As for the CE data subset, every cow was required to have the first calving recorded. In addition, data from sires with less than 10 recorded calves were discarded, as were all records from region-calving year groups with less than $20 \%$ recorded male calves or with more than 95\% records scored as 1 (Ducrocq, 2000). Contemporary groups (interaction among herd, year, and technician scoring the calving) had to include at least 5 records. Due to the low percentage of calvings scored as 4 $(0.17 \%)$, categories 3 and 4 were joined as one to minimize the extreme category problem (Moreno et al., 1997). Multiple births and 5-score calvings were not considered, because these calving performances were supposed to lack a genetic component for CE (Dekkers, 1994).

Final data set for fertility was formed by 182,885 insemination records in 90,618 lactations (including 37,236 lactations from primiparous cows) from 49,497 cows. The final data set for CE was formed by 133,681 calving records $(62,134$ from primiparous cows and 71,547 from multiparous cows). Data used are summarized in Table 1, with details regarding average pregnancy per insemination event and frequencies of calving scores.

\section{Inbreeding}

The inbreeding coefficient for each animal in the pedigree was calculated using the algorithm described by 
Table 1. Number of inseminations and pregnancy rates at each insemination event (first through fifth) ${ }^{1}$

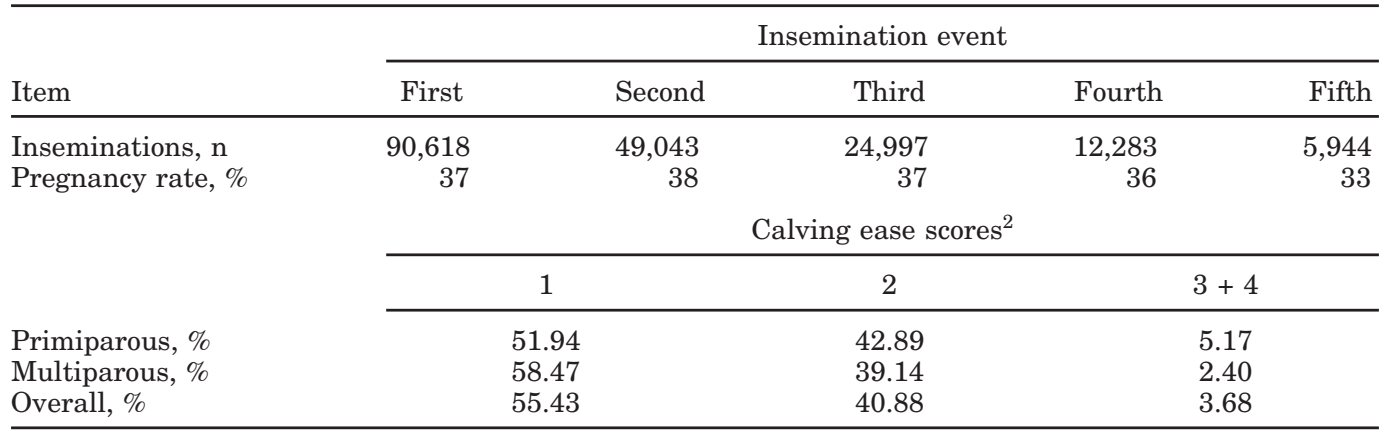

\footnotetext{
${ }^{1}$ Frequencies (in percentage points) of calving ease scores within and across parities. Figures are from cows with records.

${ }^{2} 1=$ no assistance; 2 = slight assistance; $3+4=$ calvings needing assistance and caesareans caused by size of calf.
}

Meuwissen and Luo (1992). The number of equivalent generations $(t)$ was calculated to adjust inbreeding coefficients for the available information from the pedigree of each animal. This parameter is the sum over all known ancestors of the term $(1 / 2)^{n}$, where $n=$ the number of generations between the individual and the ancestor $i$ (Maignel et al., 1996). It must be noted that this measurement of generations may not properly reflect the effect on inbreeding if the pedigree information of 1 progenitor was null or poor. However, it can be noted that such a situation never happens in the data used (Figure 1, left). Falconer and Mackay (1996) established that the average inbreeding coefficient at a given generation $t$ could be estimated using the following equation:

$$
F_{t}=1-(1-\Delta F)^{t}
$$

where $\boldsymbol{\Delta} \boldsymbol{F}=$ the inbreeding rate from one generation to the next one or new inbreeding. We propose to operate on equation [1], to set the inbreeding rate for each individual to:

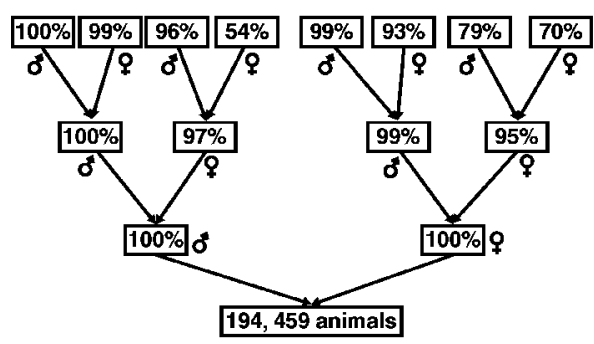

$$
\Delta F_{i}=1-\sqrt[t]{\left(1-F_{i}\right.},
$$

where $F_{i}=$ the inbreeding coefficient of individual $i$, calculated previously, and $t=$ the number of known equivalent generations for this individual, as stated earlier. This individual inbreeding rate becomes an alternative measure of inbreeding, which is adjusted for the depth of the known pedigree. This coefficient corrects the cumulative inbreeding coefficient $\mathrm{F}$ regarding the pedigree depth of the animal, and, in fact, it is not an inbreeding measurement but an indicator of the increment in inbreeding for each animal, regardless of the number of generations known in its pedigree. Therefore, it allows for easily obtaining the equivalent inbreeding coefficient at a given generation by simply applying the expression [1] above (the average number of equivalent generations was considered for the studied population). This coefficient should not be affected by the possible nonlinear increase of $\mathrm{F}$ over time, and, thus, two animals with the same inbreeding coefficient could have a different inbreeding depression effect re-

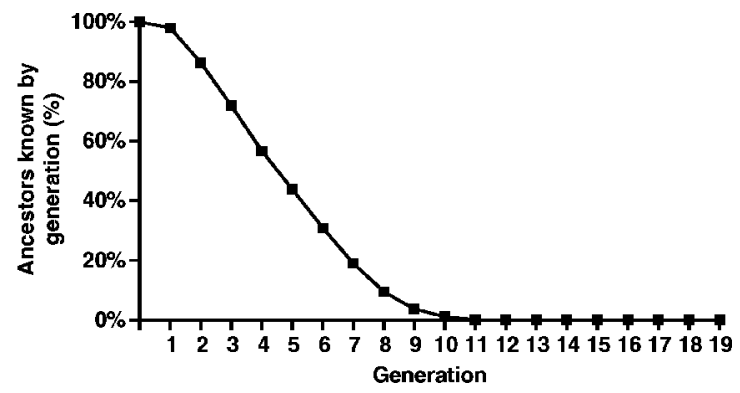

Figure 1. Completeness of pedigree in the male and female lines up to 3 generations back (left) and aggregated for all the generations known (right). 
garding the number of generations in their particular pedigree.

The inbreeding measurements, described previously, were included separately in the statistical models for INS and $\mathrm{CE}$. The inbreeding coefficients $(\mathrm{F})$ were grouped into 5 classes $[\mathrm{F} 1=(0 \leq \mathrm{F}<3.125 \%)$; $\mathrm{F} 2=$ $(3.125 \% \leq \mathrm{F}<6.25 \%) ; \mathrm{F} 3=(6.25 \% \leq \mathrm{F}<12.5 \%) ; \mathrm{F} 4=$ $(12.5 \% \leq \mathrm{F}<25 \%) ; \mathrm{F} 5=(\mathrm{F} \geq 25 \%)]$ and were included in the analyses as a categorical effect. On the other hand, $\Delta \mathrm{F}$ was considered as a linear covariate in the models. Four analyses were carried out: 2 for INS including $\mathrm{F}$ or $\Delta \mathrm{F}$ and 2 for $\mathrm{CE}$ including $\mathrm{F}$ or $\Delta \mathrm{F}$.

\section{Population Structure}

A descriptive analysis of the population used in this study was carried out using ENDOG software (Gutiérrez and Goyache, 2005). Pedigree completeness level was assessed by computing the equivalent number of generations as described before, but it was also studied by counting the proportion of known ancestors several generations back (Gutiérrez et al., 2003) and also distinguishing between male and female ancestor information. The inbreeding coefficient in the reference populations could be regressed on the equivalent number of generations to calculate the effective population size $\left(N_{e}\right)$, assuming $N_{e}=\frac{1}{2 b}$, where $b=$ the regression coefficient that roughly estimates the inbreeding rate. Also, the effective number of ancestors (Boichard et al., 1997) was computed using this reference population.

Because the inbreeding coefficient values depend on the depth and the missing information of the pedigree, a subset of data containing 194,459 cows with at least 4 equivalent generations (not actual generations) of known pedigree (reference population) was used in the statistical analyses.

\section{Models}

The models and methods used in this study were those applied in the routine genetic evaluations in the population of study and are briefly described below.

INS. A sequential threshold model was applied to INS (González-Recio et al., 2005). This model can be used to analyze an ordinal categorical trait that occurs in a sequential order, such as INS. For instance, a cow that is inseminated for a third time must have been inseminated and failed at both first and second AI. This model was assumed in analyzing INS, because it may account for all time-dependent covariates affecting this trait. Otherwise, the lack of adjusting by these effects in the model could bias the results in this study.

This model proposes a latent variable, $\omega_{i j}$, to represent the probability of the cow to pass from insemina- tion $j$ to $j+1\left(j=1\right.$ to $\left.y_{i}\right)$, where $y_{i}=$ the number of inseminations that a cow $i$ received at a given lactation. The statistical model for $\omega_{i j}$ was:

$$
\begin{aligned}
\omega_{i j}= & \mathbf{w}_{i j}^{\prime} \gamma+\mathbf{x}_{i j}^{\prime} \boldsymbol{\beta}+\mathbf{z}_{h y, i j}^{\prime} \mathbf{h y}+\mathbf{z}_{t e c, i j}^{\prime} \mathbf{t e c} \\
& +\mathbf{z}_{s s, i j}^{\prime} \mathbf{S s}+\mathbf{z}_{p, i j}^{\prime} \mathbf{p}+\mathbf{z}_{a, i j}^{\prime} \mathbf{a}+e_{i j}
\end{aligned}
$$

where $\gamma=$ the vector of cutpoints for the liability corresponding to each insemination. The systematic effects $\boldsymbol{\beta}$ in the model were as follows: effect of the inbreeding measurement ( $\mathrm{F}$ or $\Delta \mathrm{F}$ ), effect of days from calving to insemination (5 levels), effect of lactation-age at calving (16 levels), and effect of region-year-season of calving (69 levels). Other effects in the model were hy = herdyear of calving $(4,280$ levels $)$ distributed independently as $N\left(0, \mathbf{I} \sigma_{h y}^{2}\right)$, where $\sigma_{h y}^{2}=$ the variance among herd-year comparison groups; tec $=$ AI technician $(138$ levels $)$ distributed independently as $N\left(0, \mathbf{I} \sigma_{\text {tec }}^{2}\right)$, where $\sigma_{\text {tec }}^{2}=$ the variance among AI technicians; ss = service sire $(900$ levels) distributed independently as $N\left(0, \mathbf{I} \sigma_{s s}^{2}\right)$, where $\sigma_{s s}^{2}=$ the variance among service sires; $\mathbf{p}=$ environmental cow permanent effect $(49,497$ levels) independently distributed as $N\left(0, \mathbf{I} \sigma_{p}^{2}\right)$, where $\sigma_{p}^{2}=$ the environmental cow permanent effect; and $\mathbf{a}=$ additive genetic effect of the animal $(109,469$ levels $)$ distributed independently as $N\left(0, \mathbf{I} \sigma_{a}^{2}\right)$, where $\sigma_{a}^{2}=$ the additive genetic variance and $\mathbf{A}=$ the relationship matrix. Then, $\mathbf{w}_{i j}, \mathbf{x}_{i j}$, $\mathbf{z}_{h y, i j}, \mathbf{z}_{t e c, i j}, \mathbf{z}_{s s, i j}, \mathbf{z}_{p, i j}$, and $\mathbf{z}_{a, i j}$ were the respective incidence vectors. Residual $e_{i j}$ were assumed to be normally, independently, and identically distributed as $N(0,1)$. See further details in González-Recio et al. (2005) and González-Recio and Alenda (2006). The variances of herd-year, AI technician, service sire, and permanent and additive genetic effects were previously estimated and assumed as known in this study $\left(\sigma_{\text {hy }}^{2}=0.07 ; \sigma_{\text {tec }}^{2}=\right.$ $0.04 ; \sigma_{s s}^{2}=0.02 ; \sigma_{p}^{2}=0.04 ; \sigma_{a}^{2}=0.04$, respectively). Heritability of INS was 0.03 (González-Recio et al., 2005; González-Recio and Alenda, 2006). Flat priors were assumed for systematic effects. Note that the probability to receive a subsequent insemination can be interpreted as the liability to pregnancy rate.

$\boldsymbol{C E}$. A sire-maternal grandsire threshold model was considered for the analysis of CE data, which were classified in 3 categories, as described previously. This model accounts for the categorical nature of $\mathrm{CE}$ and the fact that $\mathrm{CE}$ is a trait affected by direct and maternal genetic effects. The statistical model for $\mathrm{CE}$ was as follows (López de Maturana, 2007):

$$
\lambda_{i}=\mathbf{x}_{i}^{\prime} \boldsymbol{\beta}+\mathbf{z}_{s, i}^{\prime} \mathbf{S}+\mathbf{z}_{m g s, i}^{\prime} \mathbf{m g s}+e_{i},
$$

where $\lambda_{i}=$ the liabilities to $\mathrm{CE}$, and $\boldsymbol{\beta}$ contained the following systematic effects: effect of the inbreeding 
measurement $(\mathrm{F}$ or $\Delta \mathrm{F})$ of the cow, month of calving (12 levels), sire breed (2 levels, Holstein vs. not Holstein), combination between number of parity (first and later parities) and sex of calf (4 levels), and the combination among herd, year of calving, and the technician who scored the calving $(4,407$ levels). Other effects in the model were $\mathbf{s}$ and $\mathbf{m g s}$, corresponding to the vectors of the additive genetic effects of the sire (1,269 bulls) and the maternal grandsire of the calf ( 1,886 bulls), respectively. These effects were considered as distributed following a multivariate normal distribution with mean 0 and covariance matrix $\mathbf{G}_{\mathbf{0}} \otimes \mathbf{A}$, where

$$
\mathbf{G}_{\mathbf{0}}=\left(\begin{array}{cc}
\sigma_{s}^{2} & \sigma_{s m g s} \\
\sigma_{s m g s} & \sigma_{s m g s}^{2}
\end{array}\right)
$$

and $\mathbf{A}=$ the numerator relationship matrix among sires. Then, $\mathbf{x}_{i}, \mathbf{z}_{s, i}$, and $\mathbf{z}_{m g s, i}=$ their respective incidence vectors. Residual $e_{i}$ were assumed to be normally, independently and identically distributed as $N\left(0, \sigma_{e}^{2}\right)$. The sire, maternal grandsire, and residual variances, as well as the covariance between sire and maternal grandsire genetic effects, were previously estimated and assumed as known in this study $\left(\sigma_{s}^{2}=0.004 ; \sigma_{m g s}^{2}=0.003 ; \sigma_{e}^{2}=\right.$ 0.210 ; and $\sigma_{s m g s}=0.001$, respectively, López de Maturana, 2007). The first and second thresholds were arbitrarily set to 0 and 1 , respectively. After setting these values, direct and maternal genetic (co)variances were derived following Willham (1972). The resulting direct and maternal heritabilities of $\mathrm{CE}$ were 0.07 and 0.05 , respectively.

The model was implemented using Bayesian methods with a Markov chain Monte Carlo algorithm, using threshold model (TM) program (available upon request to the authors: andres.legarra@toulouse.inra.fr). Each analysis consisted of a single chain with a length of 250,000 samples, discarding the 20,000 first samples. The lag period was considered equal to 10 . Thus, 23,000 samples were used for final inferences.

\section{Transformation to Original Scale}

Results are expressed on the liability scale, because threshold models were applied to both INS and CE (Gianola, 1982; Gianola and Foulley, 1983). For easier interpretation of the results, posterior estimates resulting from these models were transformed to the observable scale by following the procedure described in Dempster and Lerner (1950). The sequential threshold model reflects the probability to receive a subsequent insemination, which can be interpreted as pregnancy rate. Calving ease was transformed to the incidence of dystocia (percentage of calvings scored as 3 or 4).
Likewise, the posterior mean estimate on the liability scale for the first level of $\mathrm{F}(\mathrm{F}<3.125 \%)$ was arbitrarily set to the value of the phenotypic mean (37 and $3.67 \%$ for pregnancy rate and incidence of dystocia, respectively) on the liability scale. Solutions for the remaining levels of $\mathrm{F}$ were given as the differences on the observable scale with respect to this reference value. Meanwhile, a linear regression-related $\Delta \mathrm{F}$ with female fertility and $\mathrm{CE}$ on the liability scale was then transformed to the observable scale by setting $\Delta \mathrm{F}=0$ to the value of the phenotypic mean (37 and $3.67 \%$ for pregnancy rate and incidence of dystocia, respectively) on the liability scale, indicating the change in pregnancy rate and dystocia incidence when $\Delta \mathrm{F}$ increased.

\section{RESULTS AND DISCUSSION}

\section{Population Structure and Inbreeding}

The first ancestor generation of all animals included in the subset of data used (reference population) was $100 \%$ complete. The second ancestor generation was 98\% complete, and the completeness decreased progressively to $86,71,57,44,31,19,9$, and $3 \%$ for the subsequent generations (Figure 1). The average equivalent generation for the population of study was 5.68. The maximum number of known generations was 20 . The effective population size was 51, and the effective number of ancestors was 30.3 , being half of the population originated from the 13 main ancestors. Figure 2 (left) shows the $\mathrm{F}$ distribution for individuals with at least 4 equivalent generations. In the subset of cows included in the analysis, $\mathrm{F}$ ranged from 0 to $39 \%$, and the frequency distribution of $\mathrm{F}$ had a longer tail to the right. Mean and median $\mathrm{F}$ were 3 and $2 \%$, respectively, with the 75 th percentile of the distribution at $4 \%$. Figure 2 (right) shows the frequency distribution of inbreeding coefficient for cows with at least 4 equivalent generations of known pedigree data. Figure 2 (left) shows how inbreeding coefficients are grouped near to the lower limit of the intervals defined by the different powers of 0.5 . This means that the inbreeding coefficients are strongly dependent on the nearest common ancestor of the parents of each animal and might be considered a singular characteristic in dairy cattle.

\section{Effect of Inbreeding on Fertility}

Table 2 shows the posterior mean differences on the observable scale between levels of inbreeding relative to the first $\mathrm{F}$ level $(\mathrm{F}<3.125 \%)$. Cows with $\mathrm{F}$ from 6.25 to $12.5 \%$ (group F3) had a pregnancy rate of $1.68 \%$ lower than low or noninbred cows (class F1: $\mathrm{F}<3.125 \%$ ). Figure 3 shows the posterior distribution for these differences. Cows with higher inbreeding coefficients had 



Figure 2. Dispersion plot (left) and frequency distribution (right) of percentage of inbreeding (\%F) for cows with at least 4 equivalent generations of known pedigree data.

impaired fertility. The average decrease in fertility ranged from 1 to $6 \%$ for cows in F2 or F5 classes, respectively. The highest probability density intervals (HPD95\%) for these differences did not contain the zero value except the one for the differences between the level of minimum inbreeding coefficient and that of F4. This may be due to a reduced number of data in this inbreeding level, which could lead to inaccurate estimates. The distribution of the differences between the minimum level of inbreeding and the maximum one (F5) had its HPD95\% from -12.78 to $0.50 \%$, and $96 \%$ of the posterior distribution was lower than zero.

The posterior mean estimate for the coefficient of $\Delta \mathrm{F}$ on the liability scale was 4.558. A quadratic term for $\Delta \mathrm{F}$ was tested, but its posterior mean estimate was not significantly different from zero. Because the interpretation of $\Delta \mathrm{F}$ is not straightforward, this parameter was transformed to the inbreeding coefficient for an animal with an average depth of pedigree (using equation [1] and setting $t=5.68$ generations) to illustrate the evolu- tion of pregnancy rate regarding individual inbreeding rate (Figure 4). Then, for instance, the difference in pregnancy rate between a highly inbred animal (25\%) and a low or noninbred animal was 8.16 points, and the difference between a highly inbred animal (25\%) and an animal with a $3 \%$ rate of inbreeding (also belonging to group F1) was 7.24 points. Furthermore, the difference in pregnancy rate between a low or noninbred animal and another animal with a $4 \%$ rate of inbreeding was of 1.23 points (Figure 4). These differences are higher but similar to those found under the model considering inbreeding levels from the present study. The results in this study suggest that the mating plans should avoid mating close relatives. This fact might have a sensitive effect on the benefit of the farmers reducing costs due to impaired fertility.

Pearson and Spearman's correlation between EBV obtained from both models (including $\mathrm{F}$ or $\Delta \mathrm{F}$ ) was 0.99. Correlation between EBV from either model considering inbreeding measurement and a fitted model

Table 2. Mean inbreeding depression on pregnancy rate and percentage of dystocia cases for different inbreeding level ${ }^{1}$

\begin{tabular}{lllll}
\hline Functional trait & F1 $1^{2}$ vs. F2 & F1 ${ }^{2}$ vs. F3 & F1 $1^{2}$ vs. F4 & F1 ${ }^{2}$ vs. F5 \\
\hline $\begin{array}{l}\text { Pregnancy, } \% \\
\text { Mean }\end{array}$ & -1.03 & & & \\
HPD $(95 \%)$ & $(-1.72 ;-0.34)$ & $(-2.68$ & -2.00 & -6.37 \\
Dystocia, $\%$ & & & $(-6.16 ; 2.32)$ & $(-12.78 ; 0.50)$ \\
Mean & 0.12 & -0.07 & 0.71 & \\
HPD (95\%) & $(-0.04 ; 0.28)$ & $(-0.36 ; 0.22)$ & $(-0.32 ; 1.76)$ & $(-0.55 ; 4.08)$ \\
\hline
\end{tabular}

${ }^{1}$ The highest probability (95\%) density intervals (HPD) of the posterior distributions for these means are shown in parentheses. $\mathrm{F} 1=(\mathrm{F}<3.125 \%) ; \mathrm{F} 2=(3.125 \%<\mathrm{F}<6.25 \%) ; \mathrm{F} 3=(6.25 \%<\mathrm{F}<12.5 \%) ; \mathrm{F} 4=(12.5 \%$ $<\mathrm{F}<25 \%) ; \mathrm{F} 5=(25 \%<\mathrm{F})$.

${ }^{2}$ The F1 level was set to the phenotypic mean (37\% for pregnancy rate and $3.67 \%$ for dystocia cases), and, consequently, results are expressed relative to this level. 
F2 vs F1



F3 vs F1

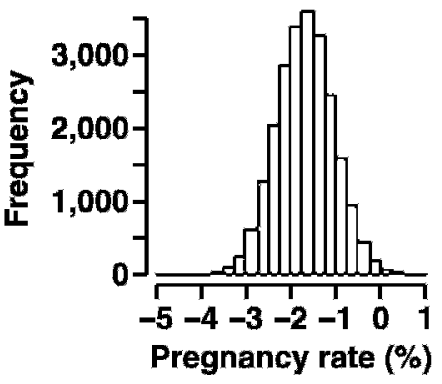

F4 vs F1

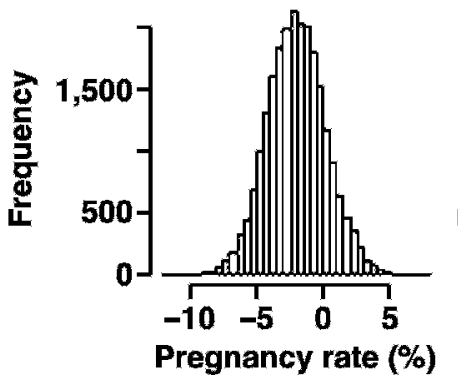

F5 vs F1

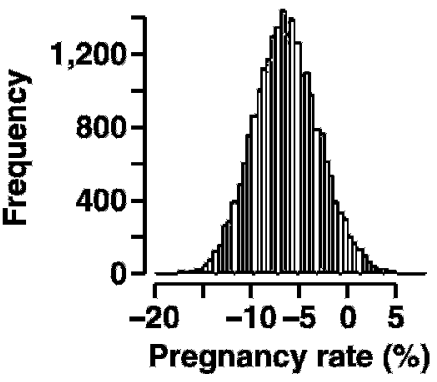

Figure 3. Histograms for the posterior distribution of the inbreeding depression (expressed as differences between different levels for the inbreeding coefficient $\mathrm{F}$ and low or noninbred cows $)$ on pregnancy rate. $\mathrm{F} 1=(\mathrm{F}<3.125 \%) ; \mathrm{F} 2=(3.125 \%<\mathrm{F}<6.25 \%)$; $\mathrm{F} 3=(6.25 \%<\mathrm{F}$ $<12.5 \%) ; \mathrm{F} 4=(12.5 \%<\mathrm{F}<25 \%) ; \mathrm{F} 5=(25 \%<\mathrm{F})$. Cows with $\mathrm{F}<3.125 \%$ were considered as low or noninbred and used as the reference level.

not including inbreeding effect was also 0.99 (EBV for all animals in the pedigree). Thus, including inbreeding (either $\mathrm{F}$ or $\Delta \mathrm{F}$ ) in the genetic evaluations would not drastically change the ranking of animals.

This inbreeding depression on fertility could explain the higher risk of culling for cows with higher $\mathrm{F}$, as reported by Sewalem et al. (2006), as well as the lower economic indices values for inbred cows shown in Croquet et al. (2006). Cassell et al. (2003a) did not find significant differences in inbreeding depression for days from calving to first service using average relationships for missing ancestors, but it is necessary to consider that this trait is affected by management and other related factors, which can mask the effect of inbreeding depression. The same authors found significant inbreeding depression on 70-d nonreturn rate in Jerseys but not in Holstein using linear models.

The results in the present study confirm that fast inbreeding rate, defined as offspring from matings between close relatives (e.g., matings between a cow and her sire, full-sibs, a cow and her grandsire, or half-sibs), is the main cause of inbreeding depression for female fertility. Cows with $6.25<\mathrm{F}<12.5 \%$ had slightly, but

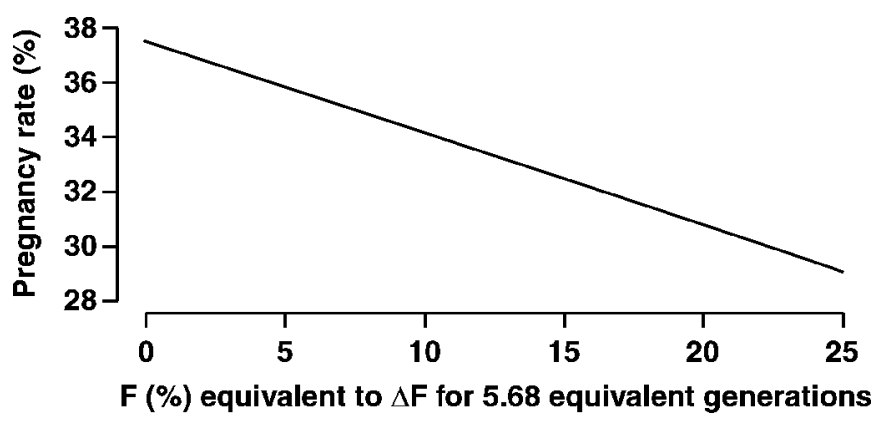

Figure 4. Regression line for inbreeding rate $(\Delta \mathrm{F})$ on pregnancy rate as a fertility trait. Converted to equivalent $\mathrm{F}(\%)$ for 5.68 equivalent generations. significantly, deteriorated fertility compared with low or noninbred cows (group F1). The decline in pregnancy rate $(-2 \%)$ might be offset for high production cows, because the higher income may compensate higher fertility cost.

As expected, both measurements ( $\mathrm{F}$ and $\Delta \mathrm{F}$ ) detected loss of reproductive fitness with increased inbreeding. The $\mathrm{F}$ coefficient is the most common parameter in most inbreeding studies, but it cannot account for the depth of known pedigree, whereas $\Delta \mathrm{F}$ is an alternative parameter that relates the augmented inbreeding of animals in the population accounting for the amount of known pedigree. This property is an advantage of $\Delta \mathrm{F}$ over $\mathrm{F}$ when a great amount of pedigree is missed. Further, analysis with $\Delta \mathrm{F}$ seems to result in a higher level of inbreeding depression loss of reproductive performance at high $\mathrm{F}$ levels.

It must be pointed out that the effect of severe inbreeding depression on fertility may not be detected in these analyses, because heifers that did not have the first calving were not included. Further, fetal inbreeding was not considered, although it might affect viability of embryonic implantation.

\section{Effect of Inbreeding on Calving Ease}

Table 2 shows the posterior mean differences on the original scale between levels of inbreeding regarding the first level $(\mathrm{F}<3.125 \%)$, as well as the HPD95\% for those estimates. Cows with an inbreeding coefficient from 12.5 to $25 \%$ (group F4) presented more dystocic calvings (by $0.71 \%$ ) higher than low or noninbred cows (group F1: F $<3.125 \%$ ). Figure 5 shows the histograms of the posterior distributions for the inbreeding depression on $\mathrm{CE}$ (expressed as differences between different levels of inbreeding). The posterior mean estimates for F4 vs. F1 and F5 vs. F1 distributions were 0.71 and $1.67 \%$, respectively. All of the HPD95\% intervals for 
F2 vs F1

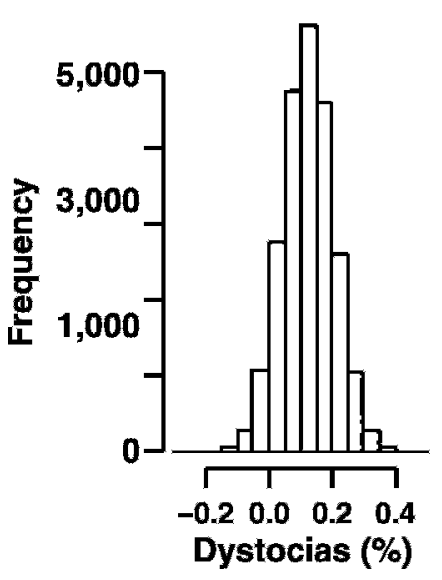

F3 vs F1

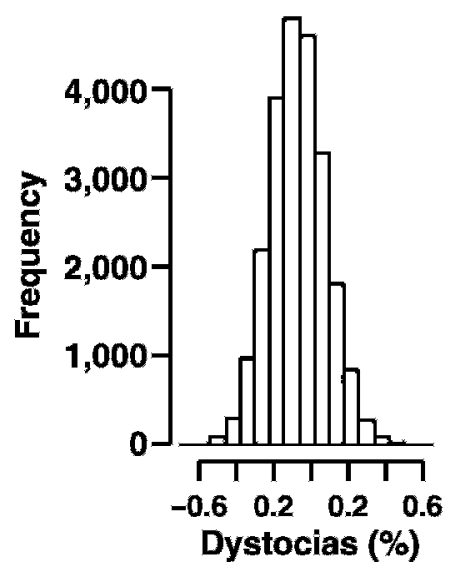

F4 vs F1

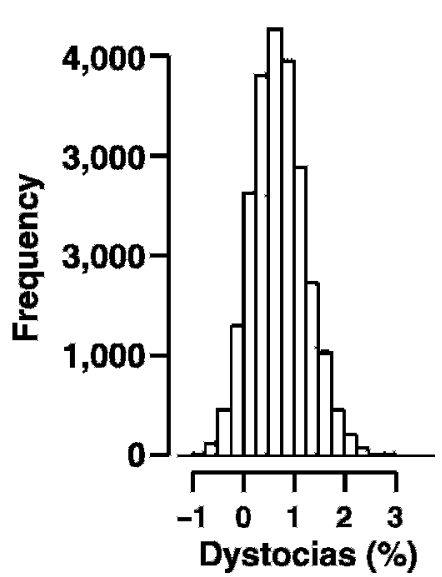

F5 vs F1

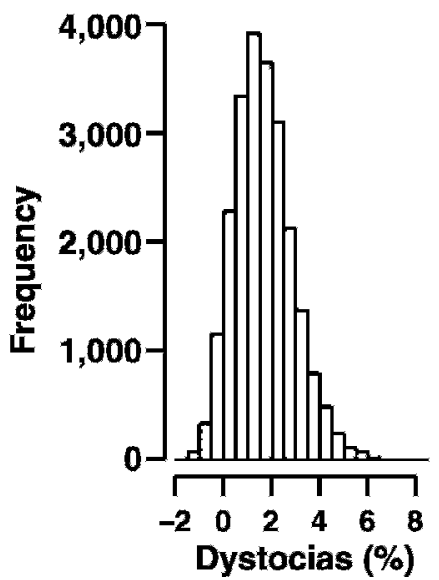

Figure 5. Histograms for the posterior distributions for the inbreeding depression (expressed as differences between different levels for the inbreeding coefficient $\mathrm{F}$ and low or noninbred cows $)$ on calving ease. $\mathrm{F} 1=(\mathrm{F}<3.125 \%) ; \mathrm{F} 2=(3.125 \%<\mathrm{F}<6.25 \%) ; \mathrm{F} 3=(6.25 \%<\mathrm{F}<$ $12.5 \%) ; \mathrm{F} 4=(12.5 \%<\mathrm{F}<25 \%) ; \mathrm{F} 5=(25 \%<\mathrm{F})$. Cows with $\mathrm{F}<3.125 \%$ were considered as low or noninbred and set to reference level.

the posterior mean differences between the levels of inbreeding in comparison with $\mathrm{F} 1$ contained the zero value. Nonetheless, it seems that higher rates of inbreeding might be related to more problems at calving, even when no significant differences can be argued, because $92 \%$ (93\%) of the posterior distribution for differences between F4 and F1 (F5 and F1) was higher than zero. This suggests that high inbred cows were more prone to have a difficult calving. However, the results from this analysis should be considered with caution, because the high posterior standard deviations for the estimates indicate the difficulty in the estimation procedure. This may be related with the low incidence of distocic parities $(3.67 \%)$ or with the genetic determinism of the trait, highly related to pelvic dimensions of a cow and size of calf. Adamec et al. (2006), in a recent study of the effect of inbreeding on calving performance, reported a consistent negative effect of inbreeding, mainly at first calving. These authors estimated that calving difficulties increased by 0.92 and $0.66 \%$ for male and female calves, respectively, when average inbreeding increased from 1.5 to $3.7 \%$.

The mean posterior estimate on the liability scale for the coefficient of $\Delta \mathrm{F}$ was not different from zero. The $\Delta \mathrm{F}$ in each cow showed no evidence of being related to changes in the incidence of dystocia. Again, the low percentage of dystocias in our population and the genetic determinism of the trait related to the pelvic dimensions of the cow and size of calf might affect this result.

In contrast to findings for female fertility, only $\mathrm{F}$, as measurement of inbreeding, detected a tendency, although not evidence, of impaired calving performance when inbreeding increased, as it has been pointed out in the discussion of the results for fertility.

The results found in this study suggest that further studies investigating the inbreeding effect on calving performance are needed.

\section{CONCLUSIONS}

Two different inbreeding measurements were used for analyzing the effect of inbreeding on fertility and $\mathrm{CE}$ : the traditional inbreeding coefficient $(\mathrm{F})$ and the individual inbreeding rate $(\Delta \mathrm{F})$, as an alternative inbreeding measurement accounting for the knowledge of the pedigree of an individual. Both measurements indicated a detriment to fertility with increased inbreeding values. The worst inbreeding depression for fertility appeared from $\mathrm{F}$ greater than $12.5 \%$, with a decrease on pregnancy rate by $2 \%$ for $12.5 \leq \mathrm{F}<25 \%$ and by $6 \%$ for $\mathrm{F} \geq 25 \%$. An increment of 0.01 units for $\Delta \mathrm{F}$ (equivalent to a traditional inbreeding coefficient of $5.5 \%$ when 5.68 generation in the pedigree are known) reduced pregnancy rate by $1.7 \%$.

The traditional inbreeding coefficient seems to underestimate the impaired reproductive performances at high $\mathrm{F}$ levels. These results confirm that fertility seems to be affected by inbreeding, being particularly severe with fast inbreeding rate. However, in this study, $\Delta \mathrm{F}$ did not detect any trend for inbreeding depression in CE. Nor did F prove that such depression exists in calving ease, but highly inbred cows tended to have higher incidence of difficult calving. The new approach to measure inbreeding $(\Delta \mathrm{F})$ should be tested in other traits and populations with different pedigree structure 
to achieve further knowledge on its full potential for inbreeding depression studies.

\section{ACKNOWLEDGMENTS}

Support by the Spanish Research Project PROFIT 010000-2003-132 (CDTI) is acknowledged. E. López de Maturana thanks the Department of Education of the Basque Country (Spain) for financial support. The authors thank the regional Holstein association (EFRIFE, AFNA, and AFRIGI) for providing the data.

\section{REFERENCES}

Adamec, V., B. G. Cassell, E. P. Smith, and R. E. Pearson. 2006. Effects of inbreeding in the dam on dystocia and stillbirths in US Holsteins. J. Dairy Sci. 89:307-314.

AIPL. 2006. Trend in inbreeding coefficients for Holstein or Red \& White. http://aipl.arsusda.gov/eval/summary/inbrd.cfm?inbrd_ tbl=HOt Accessed Feb. 2007.

Bascom, S. S., and J. Young. 1998. A summary of the reason why farmers cull cows. J. Dairy Sci. 81:2299-2305.

Boichard, D., L. Maignel, and E. Verrier. 1997. The value of using probabilities of gene origin to measure genetic variability in a population. Genet. Sel. Evol. 29:5-23.

Cassell, B. G., V. Adamec, and R. E. Pearson. 2003a. Effect of incomplete pedigrees on estimates of inbreeding and inbreeding depression for days to first service and summit milk yield in Holsteins and Jerseys. J. Dairy Sci. 86:2967-2976.

Cassell, B. G., V. Adamec, and R. E. Pearson. 2003b. Maternal and fetal inbreeding depression for 70-day nonreturn and calving rate in Holsteins and Jerseys. J. Dairy Sci. 86:2977-2983.

Croquet, C., P. Mayeres, A. Gillon, S. Vanderick, and N. Gengler. 2006. Inbreeding depression for global and partial economic indexes, production, type, and functional traits. J. Dairy Sci. 89:2257-2267.

Dechow, C. D., G. W. Rogers, and J. S. Clay. 2001. Heritabilities and correlations among body condition scores, production traits, and reproductive performance. J. Dairy Sci. 84:266-275.

Dekkers, J. C. M. 1991. Estimation of economic values for dairy cattle breeding goals: Bias due to sub-optimal management policies. Livest. Prod. Sci. 29:131-149.

Dekkers, J. C. M. 1994. Optimal breeding strategies for calving ease. J. Dairy Sci. 77:3441-3453.

Dematawewa, C. M. B., and P. J. Berger. 1997. Effect of dystocia on YIeld, fertility and cow losses and an economic evaluation of dystocia scores for Holsteins. J. Dairy Sci. 80:754-761.

Dempster, E. L., and I. M. Lerner. 1950. Heritability of threshold characters. Genetics 35:212-236.

Ducrocq, V. 2000. Calving ease evaluation of French dairy bulls with a heteroskedastic threshold model with direct and maternal effects. Interbull. Bull. 25:123-130.

Falconer, D. S., and T. F. C. Mackay. 1996. Introduction to Quantitative Genetics. 4th ed. Addison Wesley Longman, Harlow, UK.

Gianola, D. 1982. Theory and analysis of threshold characters. J. Anim. Sci. 54:1079-1096.

Gianola, D., and J. L. Foulley. 1983. Sire evaluation for ordered categorical data with a threshold model. Genet. Sel. Evol. 15:201-224.

González-Recio, O., and R. Alenda. 2006. Evaluación simultanea de la fertilidad del macho y de la hembra en el vacuno de leche. ITEA 2:215-221.
González-Recio, O., Y. M. Chang, D. Gianola, and K. Weigel. 2005. Number of inseminations to conception in Holstein cows using censored records and time-dependent covariates. J. Dairy Sci. 88:3655-3662.

González-Recio, O., M. A. Pérez-Cabal, and R. Alenda. 2004. Economic value of female fertility and its relationship with profit in Spanish dairy cattle. J. Dairy Sci. 87:3053-3061.

Groen, A. F., T. Steine, J. J. Colleau, J. Pedersen, J. Pribyl, and N. Reinsch. 1997. Economic values in dairy cattle breeding, with special reference to functional traits. Report of an EAAP-working group. Livest. Prod. Sci. 49:1-21.

Gutiérrez, J. P., J. Altarriba, C. Díaz, R. Quintanilla, J. Cañón, and J. Piedrafita. 2003. Pedigree analysis of eight Spanish beef cattle breeds. Genet. Sel. Evol. 35:43-63.

Gutiérrez, J. P., and F. Goyache. 2005. A note on ENDOG: A computer program for analysing pedigree information. J. Anim. Breed. Genet. 122:172-176.

Heins, B. J., L. B. Hansen, and A. J. Seykora. 2006. Fertility and survival of pure Holsteins versus crossbreds of Holstein with Normande, Montbeliarde, and Scandinavian Red. J. Dairy Sci. 89:4944-4951.

López de Maturana, E. 2007. Integral study of calving ease in Spanish Holstein population. Tesis doctoral. Facultad de Veterinaria. Universidad de Zaragoza, Spain.

López de Maturana, E., A. Legarra, L. Varona, and E. Ugarte. 2007a. Analysis of fertility and dystocia using recursive models, handling censored and categorical data. J. Dairy Sci. 90:2012-2024.

López de Maturana, E., E. Ugarte, and O. González-Recio. 2007b. Impact of calving ease on functional longevity and herd amortization costs in Basque Holsteins using survival analysis. J. Dairy Sci. 90:4451-4457.

López de Maturana, E., E. Ugarte, J. Komen, and J. A. M. Van Aredonk. 2007c. Consequences of selection for yield traits on calving ease performance. J. Dairy Sci. 90:2497-2505.

Maignel, L., D. Boichard, and E. Verrier. 1996. Genetic variability of French dairy breeds estimated from pedigree information. Interbull Bull. 14:49-54.

Meuwissen, T. I., and Z. Luo. 1992. Computing inbreeding coefficients in large populations. Genet. Sel. Evol. 24:305-313.

Miglior, F., B. L. Muir, and B. J. Van Doormaal. 2005. Selection indices in Holstein cattle of various countries. J. Dairy Sci. 88:1255-1263.

Moreno, C., D. Sorensen, L. A. García-Cortés, L. Varona, and J. Altarriba. 1997. On biased inferences about variance components in the binary threshold model. Genet. Sel. Evol. 29:145-160.

Sewalem, A., G. J. Kistemaker, F. Miglior, and B. J. Van Doormaal. 2006. Analysis of inbreeding and its relationship with functional longevity in Canadian dairy cattle. J. Dairy Sci. 89:2210-2216.

Thompson, J. R., R. W. Everett, and N. L. Hammershmidt. 2000. Effects of inbreeding on production and survival in Holsteins. J. Dairy Sci. 83:1856-1864.

Veerkamp, R. F., E. P. C. Koenen, and G. De Jong. 2001. Genetic correlations among body condition score, yield, and fertility in first-parity cows estimated by random regression models. J. Dairy Sci. 84:2327-2335.

Vesely, J. A., A. J. MacAllister, A. J. Lee, T. R. Batra, C. Y. Lin, G. L. Roy, J. M. Wauthy, and K. A. Winter. 1986. Reproductive performance of crossbred and purebred dairy cows. J. Dairy Sci. 69:518-526.

Weigel, K. A., and K. A. Barlass. 2003. Results of a producer survey regarding crossbreeding on US dairy farms. J. Dairy Sci. $86: 4148-4154$

Willham, R. L. 1972. The role of maternal effects in animal breeding. III. Biometrical aspects of maternal effects in animal breeding. J. Anim. Sci. 35:1288-1292. 